\title{
Development of an Ethnic Identity Measure for Americans of Middle Eastern and North African Descent: Initial Psychometric Properties, Sociodemographic, and Health Correlates
}

\author{
Ken Resnicow ${ }^{1,2} \cdot$ Minal R. Patel ${ }^{1,2} \cdot$ Molly Green $^{1} \cdot$ Alyssa Smith $^{1} \cdot$ Elizabeth Bacon $^{2}$ (D) Stefanie Goodell ${ }^{2}$. \\ Madiha Tariq $^{3}$ - Asraa Alhawli ${ }^{3}$. Nadia Syed ${ }^{3}$ - M. Lee Van Horn ${ }^{4}$. Matthew Stiffler ${ }^{3}$
}

Received: 6 May 2020 / Revised: 26 August 2020 / Accepted: 1 September 2020 / Published online: 24 September 2020

(C) The Author(s) 2020

\begin{abstract}
Background Southeast Michigan is home to the second largest Middle Eastern and North African (MENA) US population. There is increasing interest in understanding correlates of psychosocial outcomes and health behaviors in this growing population. One potentially important health correlate is ethnic identity (EI). This paper reports the development, validity, and initial correlates of a new measure of MENA identity named the MENA-IM.

Methods We used convenience sampling at locations frequented by individuals of MENA descent in southeast Michigan. We also measured EI centrality, religiosity, cultural mistrust, substance use, and health status to assess convergent and divergent validity. Exloratory and Confirmatory Factor Analysis identified three subscales, which were valid for both Arab and Chaldean respondents and were named (1) MENA cultural affiliation, (2) MENA media use, and (3) multicultural affiliation. We also created and tested a 20-item, single-factor version.

Results We obtained data from 378 adults, $73 \%$ of whom identified as Arab and 27\% as Chaldean. MENA-IM scores were higher among older, lower-educated, lower-income, non-US born, and Arabic-speaking respondents. Arab respondents reported significantly higher scores than Chaldeans. MENA-IM scores were positively associated with EI centrality and religiosity. Higher MENA-IM scores were found among those not reporting use of marijuana, alcohol, and opiates. Higher MENA-IM scores were also found among those without a self-reported history of heart disease and among those with better mental health status.

Discussion The MENA-IM has strong psychometric properties and demonstrated initial evidence of convergent and discriminant validity. In general, values on the measure were associated with better psychosocial and health status. How the measure performs with MENA populations outside of Michigan and how it may relate to other health outcomes merit investigation.
\end{abstract}

Keywords Arab American · Middle Eastern · Ethnic identity

Ken Resnicow

kresnic@umich.edu

1 Department of Health Behavior \& Health Education, University of Michigan School of Public Health, 109 Observatory Street, Room 3867 SPH I, Ann Arbor, MI 48109-2029, USA

2 University of Michigan Rogel Cancer Center, Ann Arbor, MI, USA

3 ACCESS, 6450 Maple St., Dearborn, MI 48126, USA

4 Department of Psychology, University of New Mexico, Albuquerque, NM, USA

\section{Introduction}

The US population of individuals of Middle Eastern and North African (MENA) descent numbers between two and 3.7 million [1-3]. The lower population figure represents the US census estimate [1], while the upper estimate is adjusted upward for several undercounting factors, including the fact that individuals of MENA descent are considered White under current census criteria and MENA descent must be indicated under a separate ancestry question [2,3]. By all accounts, the US MENA population has increased over the past 20 years [2].

The focus of this research is the MENA communities in southeast Michigan, who come from primarily Arabicspeaking countries. Southeast Michigan is home to the second 
largest MENA population in the USA (around 211,000 of Arab descent plus around 40,000 of Chaldean/Assyrian descent according to 2017 census estimates) with California having the largest population (around 307,000 of Arab descent plus around 31,000 of Chaldean/Assyrian descent by 2017 census estimates) [1]. Nationally, the MENA population is diverse, representing all 22 Arab League nations, with the primary countries of origin being Lebanon, Egypt, Syria, Iraq, Yemen, and Palestine as well as non-Arabic speaking countries such as Iran and Turkey. The Michigan MENA population is similar to the national population, although it has a higher percentage of Iraqis, many of whom are Christians of Chaldo-Assyrian descent and may not identify as Arab, as well as a smaller proportion of Iranians $[1,2,4]$.

There has been increasing interest in understanding the prevalence and correlates of health and health behaviors among the MENA population [5-12]. Ethnic identity (EI) [13-15] and acculturation [16-19] [20] are two potentially important predictors of health status and health behavior, widely examined in other ethnic/racial subgroups, that have recently begun to be studied in MENA populations. Although these constructs encompass overlapping dimensions (e.g., they both incorporate affiliation with one's cultural heritage and expression of cultural habits), they are not synonymous. EI can be defined as psychological, social, and behavioral affiliation with one's familial ethnicity and cultural heritage. EI then can develop and manifest both in one's native country as well as in one's adopted country. EI, when discussed within the context of immigration and assimilation, is also referred to as "enculturation" [21, 22]. However, EI and enculturation can be further differentiated with the former including not only how much one retains their original beliefs, values, and habits, but also their desire to transmit their culture to future generations. Another important distinguishing element of EI is its relative centrality to overall identity, that is, how important these values, beliefs, and practices are to one's broader definition of self. Acculturation, on the other hand, relates more to how much an individual has adopted the values and practices of their new host culture/country and not necessarily their desire to transmit their culture to future generations $[20,23$, 24]. Whereas acculturation has generally been associated with increased health risk, due to both the stress of acculturation and the fact that immigrants often adopt less health promoting behaviors, e.g., diet and substance use, endemic in their new country $[7,20,23]$, stronger ethnic identity on the other hand [24], has largely been shown to be a protective attribute [20]. Acculturation and ethnic identity can be conceived as orthogonal rather than inverse constructs, in that an individual could both acculturate to their new country and also retain a strong connection to their original culture/ethnicity.

There has been some work around measurement of acculturation/enculturation among Arab Americans, albeit with mixed findings. Jadalla and Lee adapted a measure, originally used with Hispanics, which they named the Acculturation Rating Scale for Arabic Americans-II, available both in Arabic and English (ARSAA-IIA, ARSAA-IIE) [25]. The measure yields two scores: attraction to American culture (i.e., acculturation) and attraction to Arab culture (i.e., enculturation). In one study using the ARSAA conducted among 267 Arab American women in California [26], greater attraction to American culture (acculturation) was associated with more positive health behaviors, whereas attraction to Arabic culture was unrelated to health behaviors. A second study among 297 Arab Americans surveyed in California using the ARSAA measure found that both attraction to American culture and Arab culture were associated with positive health behaviors. Specifically they found that attraction to American culture was associated with higher levels of physical activity, whereas attraction to Arabic culture was associated with better stress management and diet [27]. Finally, in a separate report of the same 297 Arab Americans, [12] attraction to American culture was associated with higher alcohol use, whereas attraction to Arab culture was associated with higher cigarette smoking.

The impact of acculturation on health behaviors may manifest differently for Arab Americans than other immigrant groups. In a sample of 1400 Arab Americans surveyed in California [9], of the 10 health behaviors and health conditions examined, second- and third-generation AAs differed little from first-generation immigrants. The authors conclude there was "little evidence for the immigrant health paradox among immigrants from Arabic-speaking countries...". It is possible that ethnic identity may be a more powerful predictor of health status than immigrant generation among Arab Americans, or it may buffer the deleterious effects of acculturation.

Together, these prior studies indicate a need to examine the role of EI among MENA individuals. This manuscript reports the development, psychometric properties, and initial sociodemographic and health correlates of a new measure of MENA ethnic identity we call the MENA-IM.

\section{Methods}

All study procedures were approved by the University of Michigan human subjects research committee in accordance with the Helsinki Declaration of 1975, as revised in 2000. Informed consent was obtained from all participants included in the study.

\section{Scale Development}

The MENA-IM was adapted from prior ethnic identity measures developed for African Americans [14, 28, 29] and Latinos $[18,19]$ (see Table 1). The key domains of EI we aimed to assess were (1) connection to prior country/region 
Table 1 Rotated factor loadings for the 20-item MENA Identity Measure (MENA-IM) for Arab and Chaldean

\begin{tabular}{|c|c|c|c|c|c|c|}
\hline \multirow[t]{3}{*}{ Item } & \multicolumn{3}{|c|}{ Arab respondents } & \multicolumn{3}{|c|}{ Chaldean respondents } \\
\hline & \multicolumn{3}{|c|}{ Total 20-item scale alpha $=.922$} & \multicolumn{3}{|c|}{ Total 20 -item scale alpha $=.903$} \\
\hline & $\begin{array}{l}\text { Factor 1: } \\
\text { cultural } \\
\text { affiliation }\end{array}$ & $\begin{array}{l}\text { Factor 2: } \\
\text { media use }\end{array}$ & $\begin{array}{l}\text { Factor 3: } \\
\text { multicultural }\end{array}$ & $\begin{array}{l}\text { Factor 1: } \\
\text { cultural } \\
\text { affiliation }\end{array}$ & $\begin{array}{l}\text { Factor 2: } \\
\text { media use }\end{array}$ & $\begin{array}{l}\text { Factor 3: } \\
\text { multicultural }\end{array}$ \\
\hline Internal consistency alpha & .81 & .88 & .83 & .86 & .88 & .80 \\
\hline $\begin{array}{l}\text { 1. Many things that are important to me are connected to my Arab } \\
\text { American identity. }\end{array}$ & .86 & & & .82 & & \\
\hline $\begin{array}{l}\text { 2. Both in my public and private thoughts, being Arab American is } \\
\text { an important part of who I am. }\end{array}$ & .80 & & & .84 & & \\
\hline $\begin{array}{l}\text { 3. Many things that make me happy are connected to the fact that I } \\
\text { am Arab American. }\end{array}$ & .80 & & & .74 & & \\
\hline $\begin{array}{l}\text { 4. In my private thoughts, I think of myself more as Arab American } \\
\text { than American. }\end{array}$ & .79 & & & .85 & & \\
\hline 5. Most of my friends are Arab American. & .64 & & & .64 & & \\
\hline $\begin{array}{l}\text { 6. When I watch television, I usually watch Arabic television } \\
\text { shows, such as ART and MBC. }\end{array}$ & & .86 & & & .89 & \\
\hline $\begin{array}{l}\text { 7. When I listen to the radio, I usually listen to Arab American radio } \\
\text { shows, e.g., CINA. }\end{array}$ & & .83 & & & .84 & \\
\hline $\begin{array}{l}\text { 8. When I look for news, I read mostly Arabic news such as The } \\
\text { Arab American News and the Dearborn Facebook page. }\end{array}$ & & .81 & & & .90 & \\
\hline $\begin{array}{l}\text { 9. I care deeply about the needs of other groups such as Native } \\
\text { Americans, African Americans, Latinos, and Asian Americans. }\end{array}$ & & & .88 & & & .91 \\
\hline $\begin{array}{l}\text { 10. I feel strongly about international human rights issues in places } \\
\text { such as Africa. }\end{array}$ & & & .83 & & & .68 \\
\hline $\begin{array}{l}\text { 11. I respect the cultural traditions of many groups, e.g., Native } \\
\text { Americans, African Americans, Latinos, and Asian Americans. }\end{array}$ & & & .72 & & & .84 \\
\hline 12. It is important to be involved in the Arab American community. & Ex & Ex & Ex & Ex & Ex & Ex \\
\hline $\begin{array}{l}\text { 13. It is important for Arab American people to educate their } \\
\text { children about Arab/Arab American art, history, music, and } \\
\text { literature. }\end{array}$ & Ex & Ex & Ex & Ex & Ex & Ex \\
\hline $\begin{array}{l}\text { 14. A thorough knowledge of Arab and Arab American history is } \\
\text { very important for our community today. }\end{array}$ & Ex & Ex & Ex & Ex & Ex & Ex \\
\hline $\begin{array}{l}\text { 15. I have a strong sense of belonging to the Arab American } \\
\text { community. }\end{array}$ & Ex & Ex & Ex & Ex & Ex & Ex \\
\hline $\begin{array}{l}\text { 16. I feel a strong emotional connection to the Middle East or North } \\
\text { Africa. }\end{array}$ & Ex & Ex & Ex & Ex & Ex & Ex \\
\hline 17. Arab Americans should give their children Arabic names. & Ex & Ex & Ex & Ex & Ex & Ex \\
\hline $\begin{array}{l}\text { 18. I keep up with political activities in the Middle East and North } \\
\text { Africa. }\end{array}$ & Ex & Ex & Ex & Ex & Ex & Ex \\
\hline $\begin{array}{l}\text { 19. It is important for Arab Americans to get back to their Middle } \\
\text { Eastern/North African roots. }\end{array}$ & Ex & Ex & Ex & Ex & Ex & Ex \\
\hline $\begin{array}{l}\text { 20. It is important for us to eat Middle Eastern/North African food } \\
\text { at home. }\end{array}$ & Ex & Ex & Ex & Ex & Ex & Ex \\
\hline
\end{tabular}

Ex excluded from the common three-factor solution, but included in the full 20 -item version

${ }^{\wedge}$ Varimax rotation

of origin (sample item: I keep up with political activities in the Middle East and North Africa), (2) desire to preserve and transmit family culture and traditions (sample item: It is important for Arab American people to educate their children about Arab/Arab American art, history, music, and literature), (3) centrality of Arab American and Chaldean identity (sample item: Both in my public and private thoughts, being Arab American is an important part of who I am), (4) respect for other cultures or multiculturalism (sample item: $I$ care deeply about the needs of other groups such as Native Americans, etc.), and (5) Arab American media use (sample item: When I watch television, I usually watch Arabic television shows, such as ART and $M B C$ ). Modifications from the African American and Latino versions were required to make the measure applicable for Arab Americans in general, and in some instances to tailor survey items for Michigan. For example, media consumption included popular international Arabic television networks such as 
ART and MBC but also local Michigan radio stations (e.g., CINA) and regional newspapers (e.g., Arab American News). All items were answered along a four-point continuum ranging from strongly disagree to strongly agree. Higher scores indicate stronger ethnic identity.

The measure was translated into Arabic using an iterative process, as per recommended methods [30]. We began by having a bilingual Arabic language expert translate the English version into Modern Standard Arabic. Translations were reviewed by bilingual professionals from our community partners. After each review, appropriate modifications were made.

After the professional reviews, we conducted cognitive pretesting of the MENA-IM and other new measures among five primarily Arabic-speaking individuals: two men and three women, ages 45-60. The interviews were conducted in both Arabic and English and were facilitated by study team members, one of whom was fluent in both languages.

Participants of the cognitive interviews suggested several modifications to the ethnic identity items. Specifically, they felt that several items could better distinguish between internal manifestations of identity (thoughts and feelings) and external behavioral items (outward expressions). To address this recommendation, we added the phrase "in my private thoughts" to relevant items. They also recommended adding "North Africa" or "North African" in addition to Arab American and Middle Eastern.

After the cognitive interviewing, the full electronic version was tested among three participants (2 in English and 1 in Arabic) and the paper version was tested among two participants (1 English, 1 Arabic). Further minor revisions were made based on the second round of pretesting feedback.

\section{Other Measures}

To explore concurrent validity, divergent validity, and predictive validity of the MENA-IM scale, we compared scores with other identity-related variables as well as health behaviors and health status.

Racial mistrust was measured using the mean of two items adapted from a prior measure [28]. The two items, each answered along a 1 (strongly disagree) to 4 (strongly agree) continuum were (1) When I think about culture/race relations in America, I get upset and (2) The United States government is trying to make things better for Arab Americans. The later item was reverse-coded prior to computing the scale score so that higher values for the two-item mean indicated greater mistrust.

Centrality of MENA identity was assessed with a single item, adapted from our prior work [28]. The item queried, "how important is being Middle Eastern/North African to your overall identity?" Responses ranged from with zero (not at all important) to 10 being (very important). This item is intended to serve as a brief measure of global ethnic identity and was assumed to be positively correlated with MENA-IM scores.

Mental health symptoms were assessed with the four-item PHQ-4 [31], which asked, "how often have you been bothered by any of the following problems?" (1) Little interest or pleasure in doing things; (2) feeling down, depressed, or hopeless; (3) feeling nervous, anxious, or on edge; and (4) not being able to stop or control worrying, all of which were answered with a 1-4 scale, with 4 being "not at all" and 1 being "nearly every day." Higher scores are indicative of better mental health status. Alpha for the four items in our sample was 0.91 .

Religiosity was measured with a three-item scale adapted from Krause [32]; 1) God/Allah put me in this life for a purpose, 2) God/Allah has a specific plan for my life, and 3) God/ Allah has a reason for everything that happens to me. Responses were 1 "strongly disagree" through 4 "strongly agree". Alpha for the three items in our sample was 0.96 .

Health behaviors assessed included current cigarette use, defined as consuming at least 100 cigarettes lifetime and currently smoking on at least some days in the past month [33]; past month alcohol use defined as consuming at least one drink of any alcoholic beverage at least once in the past 30 days [33]; past month marijuana, defined as any use in the past 30 days; past year Hookah use, defined as use on greater than 2 occasions in the past year. $[8,34]$ Lifetime pain medication use was queried with an item from the 2017 Youth Risk Behavior Survey [35]; "During your life, how many times have you taken prescription pain medicine without a doctor's prescription or differently than how a doctor told you to use it?" (count drugs such as codeine, Vicodin, OxyContin, hydrocodone, and Percocet). Use was considered more than 2 times in one's lifetime.

Self-reported medical history was assessed by asking if the respondent had ever been diagnosed with (1) cancer, (2) diabetes or high blood sugar, (3) high blood pressure or hypertension, or (4) heart condition such as heart attack, angina, or congestive heart failure. Each variable was answered NO (0) or YES (1).

Demographic variables assessed included age (collapsed into 4 groups: $18-35,30-45,45-65$, and $>65$ ), household income (collapsed into 4 groups: under $\$ 10,000 ; \$ 10,000$ to $\$ 49,999$; $\$ 50,000$ to $\$ 99,999$; and $>\$ 100,000$ ), education (collapsed into 4 groups: high school or less, some college, college graduate, graduate school or higher), religion (Muslim or Christian), native country (US-born and not US-born), Arabic spoken at home (yes or no), and Arab or Chaldean identity.

\section{Survey Administration}

Surveys were distributed at 12 settings, across three Michigan counties, that included two supermarkets frequented by the MENA community, one health clinic serving as a predominantly MENA population, one health clinic serving a predominantly Chaldean population, a state university with a high 
number of Arab American students, four mosques with a high proportion of Yemeni and Lebanese worshippers, two Chaldean churches, and a recreation center frequented by Lebanese youth.

Participants were given the option of completing surveys using pen and paper or online forms (tablet provided), with or without assistance, in English or Arabic. For those opting to complete surveys at home, we provided a self-addressed stamped envelope or a web address to complete the online version. Both paper and electronic surveys required active consent and testament that the respondent was over 18 and self-identified as Arab or Chaldean. Data collectors, many of which were fluent in both English and Arabic, were trained in interviewing by study staff. Participants received a $\$ 25.00$ gift card after completing their survey.

\section{Scale Construction and Psychometric Properties}

The 20 MENA-IM items were examined initially through exploratory factor analysis using principle components extraction, with Varimax rotation in SPSS 25 [36]. One of our goals was to create a scale that could be used for both Arab and Chaldean populations, i.e., we wanted to create a factor structure that was invariant between Arab and Chaldean respondents. We therefore identified an initial three-factor solution that appeared conceptually and statistically to fit for both the Arab and Chaldean respondents. This solution utilized 11 of the original 20 items. This three-factor solution was tested for invariance between Arab and Chaldean respondents through confirmatory factor analysis (CFA; conducted in Mplus 7).

For the CFA, items were all treated as ordinal, and measurement invariance was compared between a configural invariance model $($ Chi-square $=277.18, \mathrm{df}=82, \mathrm{RMSEA}=.09$, $\mathrm{TLI}=.98, \mathrm{CFI}=.98)$ and a model which simultaneously constrained factor loadings, item thresholds, and scaling parameters $($ Chi-square $=218.41, \mathrm{df}=120, \mathrm{RMSEA}=.08$, $\mathrm{TLI}=.98, \mathrm{CFI}=.98$ ). While the constrained model fit was somewhat weaker than the configural invariance model (Chi-square $=82.47, \mathrm{df}=38$ ), the factor structure parameters were essential similar for both groups. Given the empirical fit data, combined with the high interpretability of the threefactor solution, we proceeded with the common three factors for both the Arab and Chaldean respondents. Additional results of the exploratory and confirmatory factor analyses are available from the first author upon request.

The three factors were named MENA CULTURAL AFFILIATION (5 items), MENA MEDIA USE (3 items), and MULTICULTURAL AFFILIATION (3 items). Individual items and their factor loadings can be found in Table 1. Correlations between the three subscales ranged from .13 (between Factors 2 and 3), .36 (between Factors 1 and 2) to .58 (between Factors 1 and 3).
In addition to presenting results for the common threefactor solution, we also present results for the full 20-item scale, as some practitioners and researchers may not be working with both Arab and Chaldean populations in the same study and because the broader 20-item measure may be preferable under some situations. Scale scores for the three common factors and the overall 20-item scale measure were computed by taking the mean of items in that scale.

\section{Statistical Analyses}

We hypothesized that MENA-IM scores would be positively associated with the EI centrality item as well as the religiosity and mental health scales. Because we conceptualize ethnic identity as only partially overlapping with these constructs, we hypothesized that the associations, while significant and positive, would be of modest magnitude, thereby indicating both convergent and discriminant validity. We did not have a priori directional or magnitude hypotheses regarding the relationship between MENA-IM with cultural mistrust. We also hypothesized that higher MENA-IM scores would be associated with lower rates of substance and self-reported disease.

We first present correlations between continuous variables (e.g., other identity measures and mental health symptoms) with MENA-IM scores (Table 3) and then multiple regression results adjusting for income, education, age, gender, and place born (Table 4). For categorical independent variables, we present mean MENA-IM scores by sociodemographic variables, without covariate adjustment (Table 5). For health behaviors and medical history, which were all dichotomous variables, we report multivariate regression, using MENA-IM scores as the primary dependent variable and substance use and health history as the independent variables, adjusting for income, education, age, gender, religiosity, and place born (Table 6).

\section{Results}

We obtained responses from 394 individuals, $79 \%$ of whom completed their survey in English (see Table 2). The sample comprised $73 \%$ who identified as being of Arab descent and $27 \%$ who identified as Chaldean. The sample was majority female (63\%). About half were between ages 18 and 25 (48.8\%). Most had less than a college education (58\%) and most reported household income below $\$ 50,000$ (69\%). Two thirds were Muslim, and 33\% were Christian. Of the Christian respondents, most (89\%) were Chaldean (data not shown). The most common paternal countries of origins were Lebanon (40.8\%), Iraq (36.5\%), and Yemen (14.8\%).

Alpha for the full 20-item scale was .92 and .90 for Arab and Chaldean respondents, respectively. Alpha for the cultural affiliation factor was .81 and .86 for Arab and Chaldean 
Table 2 Sample demographics $(n=394)$

Percent

Gender

Male $(n=146)$

Female $(n=248) \quad 62.9$

Education

High school or less $(n=129)$

Some college $(n=95) \quad 24.4$

College graduate $(n=120) \quad 30.8$

Graduate school $(n=45) \quad 11.6$

Age

$18-35(n=188) \quad 48.8$

$30-45(n=90) \quad 23.4$

$45-65(n=86) \quad 22.1$

$>65(n=22) \quad 5.7$

Income

Under $\$ 10,000(n=59)$

15.4

$\$ 10,000$ to $\$ 49,999(n=204) \quad 53.4$

$\$ 50,000$ to $\$ 99,999(n=76) \quad 19.9$

$\$>100,000(n=43) \quad 11.3$

Born in the USA

Yes $(n=129)$

32.9

No $(n=263)$

67.1

Origin country of father

Lebanon $(n=160)$

40.8

$\operatorname{Iraq}(n=143)$

Yemen $(n=58)$

Egypt $(n=11)$

Palestine $(\mathrm{n}=9)$

Syria $(n=6)$

Other $(\mathrm{n}=5)$

Ethnic identity

Arab $(n=273)$

Chaldean $(n=103)$

Religion

Muslim ( $n=252$ )

Christian $(n=130)$

Other $(n=10)$

Arabic spoken at home

Yes $(n=340)$

No $(n=42)$

89.0

11.0

respondents. Alpha for the media use factor was .88 for both Arab and Chaldean respondents. And for the third factor, alpha was .83 and .80 , for Arab and Chaldean respondents.

The means for the three factors and the 20 -item total scale can be found on the bottom row of Table 5. The 20-item scale had an overall mean of 2.93, (median $=3.0$ ) a standard deviation of 0.60 , and an observed range of 1.0 to 4.0 (data not shown). The means for all three factor scores as well as the 20- item overall scale were all significantly different $(p<.01)$ between Arab and Chaldean respondents, with Chaldeans scoring lower than Arab respondents (data not shown).

As shown in Table 3, for Arab respondents, all three factor scores were significantly and positively correlated with the single item EI centrality item, whereas among Chaldean respondents, this item was significantly correlated with Factors 1 and 3 . The single centrality item was also significantly correlated with the 20 -item total score. Religiosity was significantly correlated with Factor 1 for Arab respondents, with Factors 1 and 3 for Chaldeans, and with the 20-item total score. Mental health was significantly correlated with Factor 3 for Arab respondents as well as the 20-item total score. Finally, mistrust of government was positively and significantly correlated with Factors 1 and 3 for Arab respondents and with the 20-item total score. Mistrust was negatively correlated with the media use factor among both Arab and Chaldean respondents.

All variables that had correlations at least \pm 0.20 or greater in Table 3 were still significantly associated in regression analyses, which controlled for age, gender, income, education, and place of birth (see Table 4). Correlations that were significant, but were less than \pm .20 , were no longer significant in the multivariate model, suggesting that some of the associations detected in the correlation analyses were confounded by these covariates. Two exceptions were the association between Arab American centrality and Factor 3 for Chaldeans (which became nonsignificant in multivariate analyses) and religiosity and Factor 2 for Chaldeans (which became significantly inversely associated in multivariate analyses).

As shown in Table 5, neither factor scores nor the 20-item total score differed by gender. Factor 2 scores for both Arab and Chaldean respondents, Factor 3 scores for Chaldean respondents, and the 20-item total score were significantly, inversely associated with education, that is, higher education was associated with lower scores. Factor 2 for Arab respondents and the 20-item total score were positively associated with age, that is, older respondents showed higher mean scores. The association of Factor 3 with age for Chaldeans while significant is difficult to interpret as values were highest in the 3rd age band. For income, Factor 2 scores for both Arab and Chaldean respondents, decreased as income increased. The association of Factor 3 with income for Chaldeans while significant was again difficult to interpret as values were highest in the $3 \mathrm{rd}$ income band. Factor 2 scores for both groups and the total 20-item score were significantly higher among those born outside the USA. Paternal country of birth was significantly associated with Factor 1 for Arab respondents as well as the total 20-item scale score. Highest scores were observed for those of Lebanese and Syrian descent. For Chaldeans, the entire sample reported being of Iraqi paternal lineage. Muslims showed higher scores than Christians for Factors 1 and 3 among Arab respondents and for the 20- 
Table 3 Bivariate correlations: MENA-IM factor scores and total score with identity constructs for Arab and Chaldean respondents and total sample

\begin{tabular}{|c|c|c|c|c|c|c|c|}
\hline & \multicolumn{3}{|l|}{ Arab } & \multicolumn{3}{|l|}{ Chaldean } & \multirow{2}{*}{$\begin{array}{l}\text { All } \\
\text { 20-item total } \\
\text { scale }\end{array}$} \\
\hline & $\begin{array}{l}\text { Factor 1: cultural } \\
\text { affiliation }\end{array}$ & $\begin{array}{l}\text { Factor 2: } \\
\text { media use }\end{array}$ & $\begin{array}{l}\text { Factor 3: } \\
\text { multicultural }\end{array}$ & $\begin{array}{l}\text { Factor 1: cultural } \\
\text { affiliation }\end{array}$ & $\begin{array}{l}\text { Factor 2: } \\
\text { media use }\end{array}$ & $\begin{array}{l}\text { Factor 3: } \\
\text { multicultural }\end{array}$ & \\
\hline $\begin{array}{l}\text { Arab American } \\
\text { centrality }\end{array}$ & $0.55^{\# \#}$ & $.15^{\#}$ & $.41^{\# \#}$ & $.42^{\# \#}$ & .04 & $.22^{\#}$ & $0.50^{\# \#}$ \\
\hline Religiosity & $0.12^{\#}$ & .02 & .12 & $.55^{\# \#}$ & .05 & $.46^{\# \#}$ & $0.24^{\# \#}$ \\
\hline Mental health status* & 0.06 & .05 & $.13^{\#}$ & .10 & .05 & .17 & $0.13^{\#}$ \\
\hline Mistrust & $0.25^{\# \#}$ & $-.21^{\#}$ & $.26^{\# \#}$ & -.02 & $-.25^{\# \#}$ & -.13 & $0.15^{\#}$ \\
\hline
\end{tabular}

${ }^{\#} p<.05$

\#\# $p<.01$

*Mean of 4 items; higher scores indicate more positive mental health status

item total scale score. Again, comparisons by religion were possible for Chaldeans as the entire sample reported being Christian. Finally, scores were higher among those who reported speaking Arabic at home, except for Factors 2 and 3 for Chaldean respondents.

As shown in Table 6, in multivariate analyses adjusting for age, income, education, religiosity, and place of birth, Factor 1 and Factor 3 scores among Arab respondents and the 20-item total score were significantly higher among those reporting no past-month marijuana use. Factor 1 and Factor 2 scores among Chaldean respondents and the 20-item total score were significantly higher among those who reported no past month alcohol use. Factor 1 and Factor 3 scores among Chaldean respondents were significantly higher among those who reported no lifetime opiate use.

Those with a self-reported history of heart disease had higher scores on Factor 3 (both Arab and Chaldean) and the 20 -item total scale than those reporting no history of heart disease. No other substance use behaviors or chronic diseases were associated with identity scores.

\section{Discussion}

We report the initial psychometrics and validity of a new measure of ethnic identity developed for Americans of MENA descent. The 20 items yielded three subscales with similar factor structure for both Arab and Chaldean respondents as well as a 20 -item, single-factor version. The three subscales assess discrete elements of ethnic identity: (1) positive cultural affiliation (five items), (2) MENA media use (3 items), and (3) multicultural attitudes (3 items). These scales showed high internal consistency.

Scale scores were significantly associated with identity centrality and religiosity, in the expected direction. The moderate magnitude of these associations, correlations ranging

Table 4 Adjusted ${ }^{\wedge}$ regression coefficients: MENA-IM factor scores and total scale score with identity constructs for Arab and Chaldean respondents and total sample

\begin{tabular}{|c|c|c|c|c|c|c|c|}
\hline & \multicolumn{3}{|l|}{ Arab } & \multicolumn{3}{|l|}{ Chaldean } & \multirow{2}{*}{$\begin{array}{l}\text { All } \\
\text { 20-item total } \\
\text { scale }\end{array}$} \\
\hline & $\begin{array}{l}\text { Factor 1: cultural } \\
\text { affiliation }\end{array}$ & $\begin{array}{l}\text { Factor 2: } \\
\text { media use }\end{array}$ & $\begin{array}{l}\text { Factor 3: } \\
\text { multicultural }\end{array}$ & $\begin{array}{l}\text { Factor 1: cultural } \\
\text { affiliation }\end{array}$ & $\begin{array}{l}\text { Factor 2: } \\
\text { media use }\end{array}$ & $\begin{array}{l}\text { Factor 3: } \\
\text { multicultural }\end{array}$ & \\
\hline $\begin{array}{l}\text { Arab American } \\
\text { centrality }\end{array}$ & $.49^{\# \#}$ & -.07 & $.15 \#$ & $.39^{\# \#}$ & .05 & -.03 & $.53^{\# \#}$ \\
\hline Religiosity & .07 & -.01 & .10 & $.44^{\# \#}$ & $-.26^{\#}$ & $.29^{\#}$ & $.26^{\# \#}$ \\
\hline $\begin{array}{l}\text { Mental health } \\
\text { status* }\end{array}$ & .02 & .12 & .03 & .04 & .19 & .10 & $.16^{\# \#}$ \\
\hline Mistrust & $.20^{\# \#}$ & $-.21^{\# \#}$ & $.20^{\# \#}$ & .04 & -.08 & -.14 & $.22^{\# \#}$ \\
\hline
\end{tabular}

\footnotetext{
${ }^{\wedge}$ Linear regression adjusted for age, income, education, gender, and foreign-born vs. born in the USA

${ }^{\#} p<.05$

$\#$ \#\# $p<01$

*Mean of 4 items; higher scores indicate more positive mental health status
} 
Table 5 Mean MENA-IM factor scores by demographic variables

\begin{tabular}{|c|c|c|c|c|c|c|c|}
\hline & \multicolumn{3}{|l|}{ Arab } & \multicolumn{3}{|l|}{ Chaldean } & \multirow{2}{*}{$\begin{array}{l}\text { All } \\
\text { 20-item total } \\
\text { scale }\end{array}$} \\
\hline & $\begin{array}{l}\text { Factor 1: cultural } \\
\text { affiliation }\end{array}$ & $\begin{array}{l}\text { Factor 2: } \\
\text { media use }\end{array}$ & $\begin{array}{l}20 \text {-item total } \\
\text { scale }\end{array}$ & $\begin{array}{l}\text { Factor 1: cultural } \\
\text { affiliation }\end{array}$ & $\begin{array}{l}\text { Factor 2: } \\
\text { media use }\end{array}$ & $\begin{array}{l}\text { Factor 3: } \\
\text { multicultural }\end{array}$ & \\
\hline \multicolumn{8}{|l|}{ Gender } \\
\hline Male & 3.2 & 2.3 & 3.2 & 2.6 & 2.1 & 3.0 & 2.9 \\
\hline Female & 3.3 & 2.4 & 3.4 & 2.8 & 2.0 & 3.1 & 3.0 \\
\hline Education & & \#\# & & & $\# \#$ & $\#$ & $\#$ \\
\hline $\begin{array}{l}\text { High School or } \\
\text { less }\end{array}$ & 3.3 & 2.7 & 3.4 & 2.7 & 2.5 & 2.7 & 3.0 \\
\hline Some college & 3.2 & 2.2 & 3.2 & 2.8 & 2.4 & 3.0 & 2.9 \\
\hline College graduate & 3.2 & 2.2 & 3.3 & 2.8 & 1.5 & 3.2 & 2.9 \\
\hline Graduate school & 3.0 & 1.9 & 3.3 & 2.9 & 1.6 & 3.4 & 2.8 \\
\hline Age & & \#\# & & & & $\#$ & $\# \#$ \\
\hline $18-35$ & 3.2 & 2.0 & 3.3 & 2.7 & 1.8 & 3.1 & 2.9 \\
\hline $30-45$ & 3.1 & 2.4 & 3.4 & 2.6 & 1.9 & 2.8 & 2.8 \\
\hline $45-65$ & 3.4 & 2.9 & 3.4 & 3.1 & 2.2 & 3.3 & 3.1 \\
\hline$>65$ & 3.5 & 2.8 & 3.4 & 2.7 & 2.4 & 3.0 & 3.1 \\
\hline Income & & $\# \#$ & & & $\# \#$ & $\#$ & \\
\hline Under $\$ 10,000$ & 3.2 & 2.5 & 3.4 & 2.6 & 2.5 & 2.8 & 3.0 \\
\hline $\begin{array}{c}\$ 10,000 \text { to } \\
\$ 49,999\end{array}$ & 3.2 & 2.5 & 3.3 & 2.8 & 2.5 & 3.1 & 3.0 \\
\hline $\begin{array}{c}\$ 50,000 \text { to } \\
\$ 99,999\end{array}$ & 3.2 & 2.1 & 3.3 & 2.9 & 1.3 & 3.5 & 2.8 \\
\hline$\$>100,000$ & 3.5 & 1.8 & 3.5 & 2.6 & 1.3 & 3.0 & 2.8 \\
\hline Born in the USA & & $\# \#$ & & & $\# \#$ & & $\#$ \\
\hline Yes & 3.2 & 2.0 & 3.3 & 2.9 & 1.2 & 3.2 & 2.8 \\
\hline No & 3.2 & 2.5 & 3.4 & 2.8 & 2.2 & 3.0 & 3.0 \\
\hline $\begin{array}{l}\text { Origin country of } \\
\text { father }\end{array}$ & $\#$ & & & & & & $\# \#$ \\
\hline Lebanon & 3.4 & 2.4 & 3.4 & - & - & - & 3.1 \\
\hline Iraq & 3.1 & 2.3 & 3.3 & 2.8 & 2.0 & 3.0 & 2.7 \\
\hline Yemen & 3.1 & 2.4 & 3.2 & - & - & - & 3.0 \\
\hline Palestine & 2.9 & 1.9 & 3.0 & - & - & - & 2.7 \\
\hline Egypt & 3.1 & 2.8 & 3.0 & - & - & - & 3.0 \\
\hline Syria & 3.7 & 1.9 & 3.6 & - & - & - & 3.2 \\
\hline Religion & $\#$ & & $\#$ & & & & $\# \#$ \\
\hline Muslim & 3.3 & 2.4 & 3.4 & - & - & - & 3.1 \\
\hline Christian & 2.7 & 2.0 & 2.8 & 2.8 & 2.0 & 3.1 & 2.7 \\
\hline $\begin{array}{l}\text { Arabic spoken at } \\
\text { home }\end{array}$ & $\#$ & $\#$ & $\#$ & $\#$ & & & $\# \#$ \\
\hline No & 2.7 & 1.6 & 2.8 & 2.5 & 1.8 & 3.0 & 2.5 \\
\hline Yes & 3.2 & 2.4 & 3.3 & 2.9 & 2.1 & 3.1 & 3.0 \\
\hline Total & 3.2 & 2.3 & 3.3 & 2.8 & 2.0 & 3.1 & 2.9 \\
\hline
\end{tabular}

Only reported for cells with $>5$ individuals

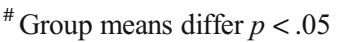

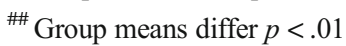

from .15 to .55 , indicates that while related, these constructs tap different dimensions of identity. We consider this pattern of results evidence of both convergent and discriminant validity of the MENA-IM.
Mistrust, while positively associated with Factor 1 for Arab respondents as well as the 20-item total score for the full sample, was negatively correlated with the media use factor among both Arab and Chaldean respondents. That is, those 
Table 6 Adjusted MENA-IM scores by substance use behaviors and self-report illness

\begin{tabular}{|c|c|c|c|c|c|c|c|}
\hline & \multicolumn{3}{|l|}{ Arab } & \multicolumn{3}{|l|}{ Chaldean } & \multirow{2}{*}{$\begin{array}{l}\text { All } \\
\text { 20-item } \\
\text { total scale }\end{array}$} \\
\hline & $\begin{array}{l}\text { Factor 1: cultural } \\
\text { affiliation }\end{array}$ & $\begin{array}{l}\text { Factor 2: } \\
\text { media use }\end{array}$ & $\begin{array}{l}\text { Factor 3: } \\
\text { multicultural }\end{array}$ & $\begin{array}{l}\text { Factor 1: cultural } \\
\text { affiliation }\end{array}$ & $\begin{array}{l}\text { Factor 2: } \\
\text { media use }\end{array}$ & $\begin{array}{l}\text { Factor 3: } \\
\text { multicultural }\end{array}$ & \\
\hline Hookah past year & NS & NS & NS & NS & NS & NS & NS \\
\hline No & 3.2 & 2.2 & 3.3 & 2.9 & 1.9 & 3.1 & 2.9 \\
\hline Yes & 3.3 & 2.4 & 3.4 & 2.5 & 2.1 & 2.9 & 3.0 \\
\hline Cigarette past month & NS & NS & NS & NS & NS & NS & NS \\
\hline No & 3.2 & 2.3 & 3.3 & 2.8 & 2.0 & 3.1 & 2.9 \\
\hline Yes & 3.2 & 2.3 & 3.4 & 2.6 & 2.0 & 2.8 & 2.8 \\
\hline Marijuana past month & $\#$ & NS & $\#$ & NS & NS & NS & $\#$ \\
\hline No & 3.3 & 2.3 & 3.4 & 2.8 & 2.0 & 3.1 & 2.9 \\
\hline Yes & 2.7 & 2.1 & 2.8 & 2.7 & 1.8 & 3.3 & 2.5 \\
\hline Alcohol past month & NS & NS & NS & $\#$ & $\#$ & NS & \#\# \\
\hline No & 3.3 & 2.3 & 3.4 & 2.9 & 2.1 & 3.1 & 3.0 \\
\hline Yes & 2.9 & 2.0 & 3.3 & 2.6 & 1.7 & 3.0 & 2.6 \\
\hline $\begin{array}{l}\text { Lifetime pain medication } \\
\text { without prescription }\end{array}$ & NS & NS & NS & $\#$ & NS & $\#$ & NS \\
\hline No & 3.3 & 2.3 & 3.3 & 2.8 & 2.0 & 3.1 & 2.9 \\
\hline Yes & 3.1 & 2.4 & 3.3 & 2.2 & 1.6 & 2.5 & 2.9 \\
\hline History of cancer & NS & NS & NS & NS & NS & NS & NS \\
\hline No & 3.2 & 2.3 & 3.3 & 2.8 & 1.9 & 3.0 & 2.9 \\
\hline Yes & 3.5 & 2.4 & 3.0 & 3.1 & 2.3 & 3.6 & 3.1 \\
\hline History of heart disease & NS & NS & $\#$ & NS & NS & $\#$ & $\#$ \\
\hline No & 3.2 & 2.3 & 3.4 & 2.8 & 1.9 & 3.1 & 2.9 \\
\hline Yes & 2.9 & 2.0 & 2.7 & 2.9 & 2.0 & 2.4 & 2.6 \\
\hline History of high blood pressure & NS & NS & NS & NS & NS & NS & NS \\
\hline No & 3.3 & 2.3 & 3.4 & 2.8 & 1.9 & 3.1 & 2.9 \\
\hline Yes & 3.0 & 2.3 & 3.2 & 2.8 & 2.1 & 3.0 & 2.9 \\
\hline History of diabetes & NS & NS & NS & NS & NS & NS & NS \\
\hline No & 3.2 & 2.3 & 3.4 & 2.8 & 2.0 & 3.1 & 3.0 \\
\hline Yes & 3.1 & 2.3 & 3.2 & 2.8 & 1.8 & 2.9 & 2.8 \\
\hline
\end{tabular}

Adjusted for age, income, education, gender, religiosity, and foreign-born vs. born in the USA

$N S$ no statistically significant difference between Yes and No groups

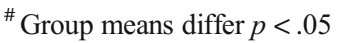

\#\# Group means differ $p<.01$

who reported higher MENA media consumption had lower scores on the mistrust measure. It appears that consumption of MENA media lowers mistrust toward the US government and decreases perceptions of discrimination. It is possible that these media sources portray US politics in a more positive light or perhaps individuals who obtain their news and entertainment from these sources are less likely to be exposed to negative aspects of US culture. Why the cultural affiliation factor was positively associated with mistrust whereas the media use factor was negatively associated with mistrust merits elucidation.

With regard to demographic correlates, higher scores on several subscales as well as the overall 20 -item scale were found among older, less-educated, lower-income, foreignborn, Arab American (compared with Chaldeans), Arabicspeaking, and Muslim compared with Christian respondents. MENA-IM scores were unrelated to gender.

The fact that older and non-US-born respondents had higher MENA-IM scores suggests that ethnic identity may weaken among subsequent generations of MENA immigrants. Higher scores among Arab compared with Chaldean respondents are consistent with prior studies that have indicated that Chaldeans may be more likely to assimilate into American society than their Arab, largely Muslim, counterparts [4]. Another reason for higher scores among Arab compared with Chaldean respondents is that some of the items 
only mentioned "Arab identity" and did not include language such as "Arab or Chaldean identity." Chaldeans may have been less likely to endorse such items. Thus, future versions of the instrument, if intended for use among the Chaldean community, may benefit from more inclusive language.

We created a three-factor version of the measure that had good fit for both Arab American and Chaldean respondents. These common factors were useful in our study as we were interested in comparing results for the two groups and is recommended when researchers want to compare these two populations. It is possible, however, that unique versions of the measure could be developed for each group that may have different items or even subscales, particularly when direct comparison between groups is not required. Finally, although the factor analyses indicated three distinct subscales, researchers and practitioners can use the single-factor version when the three-factor approach may not fit with their objectives. The 20-item total scale score showed similar construct validity as the subscales.

In terms of health behaviors and health conditions, having higher MENA-IM scores was generally protective. Specifically, MENA-IM scores were associated with better mental health status as well as lower use of alcohol, marijuana, and prescription pain medication. Higher MENA-IM scores were also found among those reporting a history of heart disease. These findings of a protective effect between ethnic identity and substance use and health outcomes is consistent with some prior studies. For example, Jadalla et al. [27] found that attraction to Arabic culture, measured somewhat similarly as the MENA-IM, was positively associated with better stress management and nutritional practices. These positive health behaviors may partially explain the protective effect of ethnic identity on heart disease and mental health that we observed.

Of the three subscales, the one measuring a multicultural worldview had the most significant associations with better health (lower heart disease and better mental) and lower substance use. The items in this subscale appear to tap how much one views themselves not only as a member of their ethnic group but also as being part of the broader world community. This multicultural worldview may exert a positive protective effect by increasing connections with not only people from their own cultural but also people from other ethnic and cultural origins. Further work understanding the protective effect of a multicultural worldview is encouraged.

In our study, the protective effect of EI remained after adjustment for birth country, and there was no interaction between EI and birth country on any outcomes (data not shown). Abuelezam et al. [9], however, found that secondgeneration AAs had higher odds of binge drinking than firstgeneration immigrants, and third-generation AAs had higher odds of overweight/obesity than first-generation immigrants. EI may function independently from acculturation, or it could serve as a buffer for its deleterious effects [9]. Our data does not allow us to examine the interaction of EI and acculturation, although this warrants future research.

Another study [12] found that attraction to Arab culture was associated with higher cigarette smoking. This is inconsistent with our findings. We found that MENA-IM scores were unrelated to cigarette or hookah use. However, some of our scales were significantly associated with lower rates of marijuana and alcohol. Thus, we found that ethnic identity was protective for some substance use behaviors rather than a risk factor. These conflicting findings may indicate that the MENA-IM may be tapping unique dimensions of ethnic identity than prior measures. There are other differences between the current and prior studies that may also contribute to inconsistent findings including the fact that our study was conducted in Michigan, where an ethnic enclave exists, whereas most of the prior cited studies were conducted in California; the MENA communities differ in many ways between these states, and these differences may impact both ethnic identity and health behaviors [1, 2, 8, 20, 37].

Given the largely protective association we observed between MENA-IM scores and substance use and health outcomes, efforts to encourage younger and second-generation MENA populations to retain their culture and traditions may be warranted, particularly interventions that incorporate and enhance ethnic identity. This may include positive ethnic socialization delivered by parents and MENA cultural institutions and venues within mainstream institutions that provide socialization opportunities for individuals of similar ethnic backgrounds (e.g. youth groups, professional associations, student groups). Similar programmatic efforts have been conducted with other racial and ethnic group and would seem worthy of investigation and evaluation for the MENA community.

\section{Limitations and Future Directions}

The survey used a community-based, convenience sample rather than a randomly drawn probability sample. Consequently, the sample recruited has several biases relative to the national and local Michigan MENA populations. For example, nationally, the median household income for MENA individuals is around $\$ 60,000$, whereas in our sample, $69 \%$ reported income under $\$ 50,000$. Our sample also appears to have lower educational attainment [2]. Nationally, $20 \%$ of Arab Americans have a post-graduate degree, compared with $11 \%$ in our sample [2]. This may be related to our sample's relatively younger age. Thus, both the values we observed for the MENA-IM and their association with demographic and health variables may not generalize to the broader MENA population in Michigan or nationally. In addition, data were self-reported, which may impact the validity of key variables such as health habits, health history, and immigration status. We are unable to quantify a response rate, given the public 
spaces where participants were recruited. Thus, we cannot determine how respondents may have differed from those who declined to participate. Finally, we did not fully measure acculturation or generational status, only where respondents were born and what languages were spoken in the home. Understanding the association of the MENA-IM with acculturation merits future research.

Despite these limitations, the initial psychometric properties of the MENA-IM suggest that the measure may be useful in characterizing ethnic identity and elucidating psychosocial and physical health outcomes in MENA populations. Research examining how the measure performs with other MENA populations outside of Michigan and how it may relate to other health outcomes beyond those reported herein is encouraged.

Funding This work was supported by the National Cancer Institute Grant P30CA046592-29-S4.

Data Availability Data sharing via repositories supported, in accordance with University of Michigan's institutional data sharing policies.

\section{Compliance with Ethical Standards}

Conflict of Interest The authors declare that they have no conflict of interest.

Ethics Approval Approval was obtained from the ethics committee of University of Michigan. The procedures used in this study adhere to the tenets of the Declaration of Helsinki.

Consent to Participate Informed consent was obtained from all individual participants included in the study.

Consent for Publication Patients signed informed consent regarding publishing their data.

\section{Code Availability Not applicable.}

Open Access This article is licensed under a Creative Commons Attribution 4.0 International License, which permits use, sharing, adaptation, distribution and reproduction in any medium or format, as long as you give appropriate credit to the original author(s) and the source, provide a link to the Creative Commons licence, and indicate if changes were made. The images or other third party material in this article are included in the article's Creative Commons licence, unless indicated otherwise in a credit line to the material. If material is not included in the article's Creative Commons licence and your intended use is not permitted by statutory regulation or exceeds the permitted use, you will need to obtain permission directly from the copyright holder. To view a copy of this licence, visit http://creativecommons.org/licenses/by/4.0/.

\section{References}

1. US Census Bureau. PEOPLE REPORTING ANCESTRY: 2017 American Community Survey 1-Year Estimates. 2018; https:// data.census.gov/cedsci/table? $\mathrm{q}=$ ancestry $\& \mathrm{t}=$ Ancestry $\& \mathrm{~g}=$ 0400000US26\&tid=ACSDT1Y2017.B04006\&hidePreview=true. Accessed August 15, 2020.

2. Arab American Institute Foundation. Arab American demographics/quick facts about Arab Americans. 2018; https:// www.aaiusa.org/demographics. .

3. Arab American Institute. Ensuring a fair and accurate count in the 2020 census: promoting representation of our communities. Washington D.C. 2019.

4. Sylvia C, Nassar-McMillan KJA, Hakim-Larson J. Biopsychosocial perspectives on Arab Americans: culture, development, and health. New York: Springer; 2014.

5. El Masri D, Koscielniak N, Piatt G, DiZazzo-Miller R, Arnetz J, Jaber LA. Barriers and facilitators to perceived diabetes selfmanagement in Arab American patients with diabetes. In: Primary Care Diabetes; 2019.

6. Alatrash M. Prevalence, perceived benefits, and perceived barriers regarding breast cancer screening among three Arab American women subgroups. J Transcult Nurs. 2019;1043659619859058.

7. Ahmed SR, Kia-Keating M, Tsai KH. A structural model of racial discrimination, acculturative stress, and cultural resources among Arab American adolescents. Am J Community Psychol. 2011;48(3-4):181-92.

8. Neumayer H WS, Fussman C, McKane P. Health risk behaviors among Arab adults within the state of Michigan: 2016 Arab behavioral risk factor survey. Lansing, MI: Michigan Department of Health and Human Services, Lifecourse Epidemiology and Genomics Division and Health Disparities Reduction and Minority Health Section;2017.

9. Abuelezam NN, El-Sayed AM, Galea S. Relevance of the "immigrant health paradox" for the health of Arab Americans in California. Am J Public Health. 2019;109(12):1733-8.

10. Ayyash M, Ayyash M, Bahroloomi S, Hamade H, Makki M, Hassouneh S, et al. Knowledge assessment and screening barriers for breast cancer in an Arab American community in Dearborn. Michigan J Commu Health. 2019;44(5):988-97.

11. Abuelezam NN, El-Sayed AM, Galea S. The health of Arab Americans in the United States: an updated comprehensive literature review. Front Public Health. 2018;6:262.

12. Jadalla A, Lee J. The relationship between acculturation and general health of Arab Americans. J Transcult Nurs. 2012;23(2):159-65.

13. Thompson VS. A multidimensional approach to the assessment of African American racial identification. West J Black Stud. 1991;15(3):154-8.

14. Resnicow K, Soler R, Braithwaite R, Selassie M, Smith M. Development and validation of a racial identity scale for African American adolescents: the survey of black life. J Black Psychol. 1999;25(2):171-88.

15. Caldwell CH, Zimmerman MA, Bernat DH, Sellers RM, Notaro PC. Racial identity, maternal support, and psychological distress among African American adolescents. Child Dev. 2002;73(4): 1322-36.

16. Landrine $\mathrm{H}$, Klonoff E. African American acculturation: deconstructing race and reviving culture. Thousand Oaks: Sage Publication, Inc.; 1996.

17. Ayala GX, Mickens L, Galindo P, Elder JP. Acculturation and body image perception among Latino youth. Ethn Health. 2007;12(1): 21-41.

18. Davis RE, Resnicow K, Couper MP. Survey response styles, acculturation, and culture among a sample of Mexican American adults. J Cross-Cult Psychol. 2011;42(7):1219-36.

19. Davis RE, Peterson KE, Rothschild SK, Resnicow K. Pushing the envelope for cultural appropriateness: does evidence support cultural tailoring in type 2 diabetes interventions for Mexican American adults? Diabetes Educ. 2011;37(2):227-38. 
20. Amer M. Arab American acculturation and ethnic identity across the lifespan: sociodemographic correlates and psychological outcomes. In: Nassar-McMillan KJA SC, Hakim-Larson J, editors. Biopsychosocial perspectives on Arab Americans: culture, development, and health. New York: Springer; 2014. p. 153-75.

21. Yoon E, Langrehr K, Ong LZ. Content analysis of acculturation research in counseling and counseling psychology: a 22-year review. J Couns Psychol. 2011;58(1):83-96.

22. Yoshihama M, Blazevski J, Bybee D. Enculturation and attitudes toward intimate partner violence and gender roles in an Asian Indian population: implications for community-based prevention. Am J Community Psychol. 2014;53(3-4):249-60.

23. Thomas J, O'Hara L, Quadflieg S, Weissgerber SC. Acculturation, out-group positivity and eating disorders symptoms among Emirati women. \Eat Weight Disorders Stud Anorexia Bulimia Obes. 2018;23(2):241-6.

24. Berry JW. Immigration, acculturation, and adaptation. Appl Psychol. 1997;46(1):5-34.

25. Jadalla A, Lee J. Validation of Arabic and English versions of the ARSMA-II acculturation rating scale. J Immigr Minor Health. 2015;17(1):208-16.

26. Hardan-Khalil K. Factors affecting health-promoting lifestyle behaviors among Arab American women. J Transcult Nurs. 2019;1043659619859056.

27. Jadalla AA, Hattar M, Schubert CC. Acculturation as a predictor of health promoting and lifestyle practices of Arab Americans: a descriptive study. J Cult Divers. 2015;22(1):15-22.

28. Davis RE, Alexander G, Calvi J, Wiese C, Greene S, Nowak M, et al. A new audience segmentation tool for African Americans: the black identity classification scale. J Health Commun. 2010;15(5): $532-54$.
29. Resnicow K, Ross D. Development of a racial identity questionnaire for African American adults. J Black Stud. 1997;23(2):23954.

30. Sperber AD. Translation and validation of study instruments for cross-cultural research. Gastroenterology. 2004;126(1 Suppl 1): S124-8.

31. Kroenke K, Spitzer RL, Williams JB, Lowe B. An ultra-brief screening scale for anxiety and depression: the PHQ-4. Psychosomatics. 2009;50(6):613-21.

32. Krause N. Religious meaning and subjective well-being in late life. J Gerontol B Psychol Sci Soc Sci. 2003;58(3):S160-70.

33. National Cancer Institute. Health Information National Trends Survey (HINTS). 2018.

34. Hekman KWS, Fussman C, Lyon-Callo S. Health risk behaviors among Arab adults within the state of Michigan: 2013 Arab behavioral risk factor survey. Lansing: Michigan Department of Health and Human Services, Lifecourse Epidemiology and Genomics Division and Health Disparities Reduction and Minority Health Section; 2015.

35. Center for Disease Control and Prevention (CDC). Youth risk behavior survey. 2017.

36. IBM. SPSS Statistics for Windows, Version 25.0. [computer program]. Armonk: IBM Corp; 2017.

37. Echeverría S, Diez-Roux AV, Shea S, Borrell LN, Jackson S. Associations of neighborhood problems and neighborhood social cohesion with mental health and health behaviors: the Multi-Ethnic Study of Atherosclerosis. Health Place. 2008;14(4):853-65.

Publisher's Note Springer Nature remains neutral with regard to jurisdictional claims in published maps and institutional affiliations. 